\title{
Morphometric Differences Between Golden Redfish (Sebastes marinus) and Beaked Redfishes (S. mentella and S. fasciatus)
}

\author{
D. J. Power \\ Department of Biology, Memorial University of Newfoundland \\ St. John's, Newfoundland, Canada A1C 5S7 \\ and \\ $\mathrm{I}-\mathrm{H}$ sun $\mathrm{Ni}$ \\ Fisheries Research Branch, Department of Fisheries and Oceans \\ Northwest Atlantic Fisheries Centre, P. O. Box 5667 \\ St. John's, Newfoundland, Canada A1C 5X1
}

\begin{abstract}
Morphometric characters were investigated to provide criteria, in addition to morphological differences that are presently employed, for species identification of Atlantic redfishes (genus Sebastes). The study involved the analysis of morphometric data for a sample of redfish which was collected in the Labrador-Newfoundland region in 1958 and initially separated into two groups (Sebastes marinus and beaked redfish) on the basis of color, eye size and beak shape. Standard length was used as a covariate to adjust the morphometric data because $S$. marinus were on the average larger than beaked redfishes. Discriminant analyses of (a) 17 morphometric characters resulted in an 11-variable discriminant function where $65 \%$ of the variability was explained by the groups, (b) the two traditional discriminatiors (length of symphyseal tubercle and width of orbit) resulted in a function where $56 \%$ of the variability was explained by the groups, and (c) the remaining 15 morphometric characters resulted in a 9-variable function where $58 \%$ of the variability was explained by the groups. The results demonstrated good (87-90\%) separation of golden redfish (S. marinus) and beaked redfishes ( $S$. mentella and $S$. fasciatus). Length of symphyseal tubercle (beak), orbit width, body depth at the position of the pectoral fins, interorbital width, depth of caudal peduncle, and width of pectoral fin base were determined as good morphometric discriminators.
\end{abstract}

\section{Introduction}

Morphological differences between Sebastes marinus and $S$. mentella were described by Templeman and Sandeman (1957) who referred to the two varieties of redfish as marinus-type and mentella-type. Subsequently, the classification problem became complicated with the suggestion of a third species ( $S$. fasciatus) by Barsukov (1968). This species closely resembles $S$. mentella in external appearance and both species have been termed "beaked redfishes". Ni (1981) reported that the passage of the extrinsic gasbladder musculature between different ventral ribs was the most accurate character for distinguishing S. mentella from S. fasciatus. Power and $\mathrm{Ni}$ (1982) studied the same character in $S$. marinus and concluded that the morphology of this muscle was significantly different among the three redfish species of the Northwest Atlantic. However, use of this character in distinguishing the three species is very time-consuming and requires special skills. Ni (MS 1981), in an application of factor analysis of 29 morphological characters, suggested that the angles of the first and the second preopercular spines and the symphyseal tubercle were good discriminators for the three species of redfish in the Northeast Atlantic (S. marinus, S. mentella and S. viviparus). Misra and $\mathrm{Ni}$ (1983) applied a discriminant analysis (with covariance) to morphometric data for $S$. mentella and S. fasciatus and found that seven characters provided good separation of the species. Because specimens of $S$. fasciatus were smaller than those of $S$. mentella, thus warranting correction of morphometric differences due to size (Bliss, 1970), they used standard length as a covariate.

There are no reports of previous attempts to quantify morphometric characters as being useful in the separation of $S$. marinus and the beaked redfishes. Although the morphological differences between large specimens of $S$. marinus and beaked redfishes were noted by Templeman and Sandeman (1957), it is useful to have statistical confirmation of the differences based on morphometrics. Not only would such a classification complement existing criteria for distinguishing S. marinus from beaked redfishes, but it would also serve as a guideline for future field investigations. Therefore, discriminant analysis, with standard length as covariate, was employed to discover good discriminators between $S$. marinus and beaked redfishes. This study has three purposes (a) to statistically evaluate the discriminatory power of morphometry in separating S. marinus and beaked redfishes, (b) to discover whether morphometric characters that were not used in the initial classification may be useful as discrmina- 
tors, and (c) to determine the best subset of all available morphometrics by using stepwise discriminant analysis.

\section{Materials and Methods}

The redfish specimens were collected during bottom-trawl surveys by research vessels of the Newfoundland Biological Station in 1958. Hamilton Bank off Labrador and Flemish Cap east of Newfoundland were chosen as the collection sites, because these areas were known to contain a mixture of $S$. marinus and beaked redfishes. The specimens (Table 1) were initially classified by color (orange for S. marinus and red for beaked redfishes), size of eye (generally smaller in $S$. marinus than in beaked redfishes of the same size), and symphyseal tubercle (blunt in S. marinus and sharp in beaked redfishes) (Templeman and Sandeman, 1957). Specimens which were not identified and were referred to as "intermediate" by collectors were not used in the analysis. The morphometric characters and their abbreviations are listed in Table 2.

TABLE 1. Sample details for collections in 1958 of golden redfish ( $S$. marinus) and beaked redfishes used in this study of morphometric differences.

\begin{tabular}{|c|c|c|c|c|c|c|}
\hline \multirow[b]{2}{*}{ Month } & \multirow{2}{*}{$\begin{array}{c}\text { Locality } \\
\text { (NAFO Div.) }\end{array}$} & \multicolumn{2}{|c|}{ Position } & \multirow{2}{*}{$\begin{array}{l}\text { Depth } \\
\text { range } \\
(\mathrm{m})\end{array}$} & \multirow{2}{*}{$\begin{array}{c}\text { Bottom } \\
\text { temperature } \\
\left(C^{\circ}\right)\end{array}$} & \multirow{2}{*}{$\begin{array}{c}\text { No. of } \\
\text { redfish } \\
\text { specimens }\end{array}$} \\
\hline & & Latitude & Longitude & & & \\
\hline Jun & $\begin{array}{c}\text { Flemish Cap } \\
(3 \mathrm{M})\end{array}$ & $47^{\circ} 26^{\prime}-47^{\circ} 30^{\prime} \mathrm{N}$ & $45^{\circ} 50^{\prime}-45^{\circ} 52^{\prime} W$ & $276-314$ & $4.0-4.1$ & $\begin{array}{l}58 \text { golden } \\
39 \text { beaked }\end{array}$ \\
\hline Aug & $\begin{array}{l}\text { Hamilton Bank } \\
\text { (2J) }\end{array}$ & $54^{\circ} 45^{\prime}-54^{\circ} 52^{\prime} \mathrm{N}$ & $53^{\circ} 40^{\prime}-54^{\circ} 12^{\prime} W$ & $256-549$ & $1.3-3.5$ & $\begin{array}{l}78 \text { golden } \\
164 \text { beaked }\end{array}$ \\
\hline Oct & $\begin{array}{l}\text { Hamilton Bank } \\
\text { (2J) }\end{array}$ & $53^{\circ} 00^{\prime}-53^{\circ} 14^{\prime} \mathrm{N}$ & $52^{\circ} 08^{\prime}-52^{\circ} 31^{\prime} \mathrm{W}$ & $256-549$ & $2.6-4.0$ & $\begin{array}{l}61 \text { golden } \\
96 \text { beaked }\end{array}$ \\
\hline Nov & $\begin{array}{c}\text { Flemish Cap } \\
(3 M)\end{array}$ & $47^{\circ} 27^{\prime}-47^{\circ} 55^{\prime} \mathrm{N}$ & $45^{\circ} 50^{\prime}-46^{\circ} 19^{\prime} \mathrm{W}$ & $272-457$ & $3.7-3.9$ & $\begin{array}{l}36 \text { golden } \\
30 \text { beaked }\end{array}$ \\
\hline
\end{tabular}

TABLE 2. Morphometric characters and methods of measuring redfish specimens. (Except where noted, linear measurements were made to nearest $0.5 \mathrm{~mm}$ and, where applicable, on left side of fish.)

\begin{tabular}{|c|c|c|}
\hline Abbreviation & Character & Method of measurement \\
\hline BODEPANA & Body depth at anal fin & $\begin{array}{l}\text { Dorso-ventral measurement at base of first anal spine perpendicular to main } \\
\text { longitudinal axis of fish }\end{array}$ \\
\hline BODEPPEC & Body depth at pectorals & $\begin{array}{l}\text { Dorso-ventral measurement at base of first dorsal spine perpendicular to main } \\
\text { longitudinal axis of fish }\end{array}$ \\
\hline BODYWEIG & Body weight & Gilled and gutted weight of fish $(\mathrm{g})$ \\
\hline BODYWIDT & Body width & $\begin{array}{l}\text { Width of body at base of first dorsal spine between parallel lines perpendicular } \\
\text { to longitudinal axis of fish }\end{array}$ \\
\hline CAUDPEDS & Depth of caudal peduncle & Dorsal-ventral depth at narrowest part of caudal peduncle \\
\hline CRANRIDG & Cranial ridge width & Width at anterior edge where ridges cease to be visible \\
\hline HEADLENG & Head length & Anterior tip of upper jaw to posterior edge of operculum \\
\hline INSIBEAK $^{\mathrm{a}}$ & Beak with jaw attachment & Tip of beak (syphyseal tubercle) to inside of lower jaw \\
\hline INTEREYE & Interorbital width & Width between orbits at location of spines on anterior dorsal edge of eye \\
\hline ORBIT & Orbit width & $\begin{array}{l}\text { Anterior edge of orbit opposite most anterior nostril to a point diametrically } \\
\text { opposite }\end{array}$ \\
\hline OUTSBEAK ${ }^{\mathrm{a}}$ & Beak without jaw attachment & Tip of beak to center of outside of lower jaw \\
\hline PECTBASE & Width of pectoral fin base & Width of fleshy attachment of pectoral fin \\
\hline PECTLENG & Length of pectoral fin & $\begin{array}{l}\text { Length from crease made when left pectoral is raised from body to longest ray } \\
\text { when fin lies flat on body }\end{array}$ \\
\hline POSTPECT & Postpectoral length & Snout to posterior end of pectoral fin ray \\
\hline SNOTANAL ${ }^{\mathrm{b}}$ & Preanal length & Snout to anterior base of first anal spine \\
\hline SNOTDORS $^{b}$ & Predorsal length & Snout to anterior base of first dorsal spine \\
\hline SNOTLENG & Snout length & Tip of upper jaw to front margin of the orbit \\
\hline STANLENG & Standard length & Anterior part of upper jaw to end of hypural \\
\hline
\end{tabular}

a Measurement to nearest $0.1 \mathrm{~mm}$.

b Measurement to the relevant posterior point on a line parallel to longitudinal axis of fish. 
Logarithmic (base 10) transformation was applied to the data, because multivariate normality is usually more closely approximated by logarithms of the values than the actual values. All statistical analyses were performed with the BMDP computer programs of Dixon et al. (1981).

The log-transformed data were initially subjected to a principal components analysis (PCA). In PCA, the data are treated as a whole, and, depending on the pattern of covariation that exists, may provide a means of obtaining clusters that represent groups when the plots are viewed. PCA provides purely descriptive results and is, therefore, suitable for use on a heterogeneous population, because it does not require assumptions about the data matrix (Neff and Smith, 1978). The analysis initially extracts the components in the direction of greatest variance. These components are linear combinations of the original variables. Subsequent extraction of components is in the direction of the next greatest variance orthogonal to (uncorrelated with) each previous component extracted. It is possible to retain the first $n$ components with the confidence that they extract most of the total variation in the data. Hence, the parsimony of such an analysis allows a reduction in the number of variables from $p$ correlated variables to $n<p$ uncorrelated components (Cooley and Lohnes, 1971).

The primary purpose of PCA is data reduction, whereby an observation may be represented by a small number of component scores instead of the original larger number of variables, with little loss of information. One offshoot of PCA in recent years has been its use in determining whether grouping is inherent in a data set. In such cases, principal component plots have been viewed for patterns of similarity (or dissimilarity) of component scores when groups are known to exist. Neff and Smith (1978) used PCA to discover the location of hybrids between two parental populations on a plot of PC1 against PC2. It was with this in mind that PCA was performed on the Sebastes data to see if the component scores of $S$. marinus and beaked redfishes would cluster on such a plot separately (BMDP4M program). In essence, separate clusters would confirm that the specimens in this study were initially separated correctly into their respective groups. The PCA was performed on the correlation matrix.

A valid discriminant analysis must be preceded by a significant difference in population mean vectors. Multivariate analysis of variance (MANOVA) is a technique for testing the equality of mean vectors (centroids) between groups. In this study, the mean standard length of $S$. marinus specimens $(354.8 \mathrm{~mm})$ was larger than that of the beaked redfishes (287.4 $\mathrm{mm}$ ). In order to eliminate the effect of this difference in standard length, because it masks other differences between the groups, the analysis involved a combina- tion of regression analysis (BMDP6R program) and multivariate analysis of variance (BMDP4V program). Each variable is regressed upon the covariate, thereby providing a means of removing the effect of the covariate, and all subsequent analyses are performed on the residuals of those variables. The result is the same as comparing groups with the standard length. The technique assumes that the slope of the regression line of each variable on the covariate is the same for both groups.

Hotelling's $T^{2}$ (Anderson, 1958) was considered to be the appropriate test-statistic for determining differferences between species. If a multivariate difference existed between species, univariate statistics were examined to determine which morphometric characters differed. Levene's test (calculated by BMDP3D program) was used to check for equality of variance, because it is considered to be more robust than the usual F-statistic (Brown and Forsythe, 1974). The appropriate t-test was then used to determine whether the means differed significantly. If the sample variances were found to be similar, the t-statistic was computed by using the variance of the pooled data for both samples. If the sample variances were found to differ significantly, the t-statistic (Welch-Aspin method) was based on the weighted mean of the variances of the two samples.

A bias arises in the application of discriminant analysis if the sample data used in calculating the discriminant function is also used by the function to classify the observations into groups. A procedure used by BMDP7M program to reduce this bias is a jacknife validation (Lachenbruch and Mickey, 1968). Each specimen was classified as $S$. marinus or beaked redfish according to the scores obtained from the discriminant function which was calculated by using all data except the observations for the specimen being classified.

In this study, the following assumptions were made: (a) multinormal-distributed observations; (b) correct initial classification of observations into their respective groups, and equality of dispersion matrices (for discriminant analysis); (c) common variance of error terms at each level of the covariate (for regression); and (d) equality of regression slopes between groups for each variable on the covariate. This assumption of equality of regression slopes, as noted by Misra and $\mathrm{Ni}$ (1983) for beaked redfishes, seems tenable enough biologically to procede with multivariate analysis of variance (MANOVA) for S. marinus and beaked redfishes.

Discriminant analysis was performed in this study on three sets of variables: set A containing data for all 17 morphometric characters (Table 2), set B consisting 
of data for only the characters OUTSBEAK and ORBIT, and set $C$ involving all variables except those in set $B$. Only specimens with measurements for all characters in each set were used in the analysis.

\section{Results and Discussion}

Principal components analysis resulted in the extraction of two components (PC1 and PC2) which explained $95.3 \%$ of the variability in the data set. Plotting of the PC1 and PC2 scores results in two clusters (Fig. 1), when each specimen was identified on the plot according to the morphological characters described by Templeman and Sandeman (1957). This verified that the initial separation of the redfish into two groups was very good. The PC2 scores for beaked redfish were mostly positive and those for $S$. marinus were mostly negative. PC1 can be considered as a "size" factor and PC2 as a "shape" with some "size" factor. Although it is difficult to interpret PC2 with confidence, it is interesting to note that values for two of the original discriminators were high (ORBIT $=0.350$ and OUTSBEAK = 0.795), perhaps implying that this is a "species shape differences" component.

The multivariate test of equality of group centroids, after the data were adjusted by the covariate STANLENG, resulted in a highly significant rejection of the null hypothesis that $S$. marinus and beaked redfishes have the same group centroid (Hotelling $T^{2}=$ 836.0, corresponding F-statistic $=47.4, \mathrm{P}<0.001$ ). Univariate tests of common variance was accepted

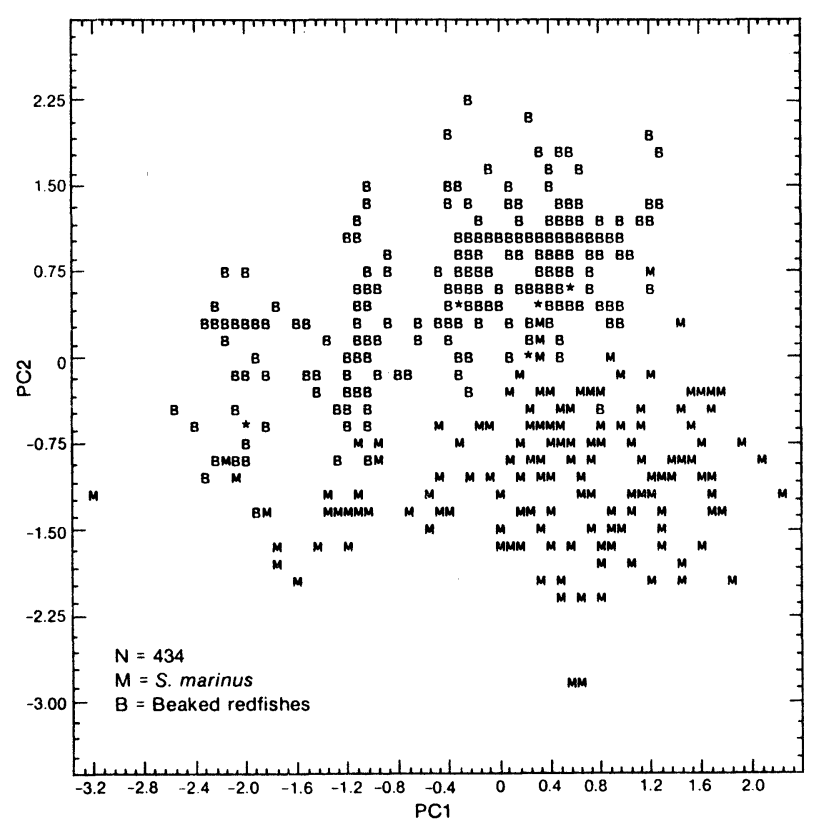

Fig. 1. Plot of principal component 1 (PC1) against principal component 2 (PC2) for $S$. marinus and beaked redfishes. (PC1 accounted for $89.3 \%$ of the variation and PC2 accounted for $6.0 \%$.)
$(P>0.05)$ for all variables except OUTSBEAK $(0.01<P$ $<0.05$ ), implying that the assumption of equality of disperson (covariance) matrices in both groups may not be extremely violated (Table 3 ). Univariate t-tests for equality of group means prior to adjustment with the covariate STANLENG indicated that the means for ORBIT were similar in both groups $(P>0.8)$. However, Templeman and Sandeman (1957) observed that the eye of $S$. marinus is smaller than that of beaked redfishes. This, coupled with the larger sizes of $S$. marinus than beaked redfishes in the sample, leads statistically to the conclusion that ORBIT is the same in both groups. Because fish size was believed to be responsible for masking possible differences between the groups, a correction to the morphometric variables was considered to be warranted. Adjustment of the variables with covariate STANLENG provided this correction, and the result for ORBIT was a highly significant difference between $S$. marinus and beaked redfishes (Table 3 ).

The first discriminant analysis of all 17 variables (Set $A$ adjusted by covariate STANLENG) was to determine good discriminators. The variables which distinguished $S$. marinus from beaked redfishes on a decreasing scale (of F-values) were OUTSBEAK (38.3), BODEPPEC (26.2), CAUDPEDS (15.8), INTEREYE (15.1), ORBIT (14.3), PECTBASE (12.1), SNOTLENG (10.4), PECTLENG (5.8), SNOTANAL (5.5), INSIBEAK (5.0) and CRANRIDG (4.2). The discriminant function was used to correctly classify $91.5 \%$ of the individuals by the resubstitution method and $90.3 \%$ by the bias-reducing jackknife method (Table 4). Wilk's $\lambda$ was reduced from 1.000 to 0.373 after six variables were entered into the function and changed only to 0.349 after entering the next five variables. This implies that the discrimination can be nearly as good with fewer variables even though the stepwise procedure chose the "best" 11 of the 17 available variables. Lachenbruch (1975) pointed out that, although the stepwise procedure selects the "best" set of variables, there is a good possibility that some of these contribute to considerable variability in the system. Canonical correlation between the variables entered into the function (canonical variates) and the dummy variable representing the groups is 0.807 . The square of this value $(65.1 \%)$ is the proportion of variability in the function that is explained by the groups (Klecka, 1975).

The second discriminant analysis (Set $B$ adjusted by the covariate STANLENG) involved only the measurements for the two traditional discriminators (OUTSBEAK and ORBIT) that were used by Templeman and Sandeman (1957). The function was used to correctly classify $87.2 \%$ of the specimens by both the resubstitution and the jackknife methods (Table 4). The F-values for both variables were high, with OUTSBEAK (83.0) being more important than ORBIT (62.7). Values of 
TABLE 3. Means and standard errors of log-transformed morphometric data for $S$. marinus and beaked-redfishes, Levene's equality of variance test and appropriate t-tests for differences before and after adjustment of the variables by the covariate STANLENG (NS = not significant, and significant levels are $P<0.05\left({ }^{*}\right)$ and $P<0.01\left(^{* *}\right)$.)

\begin{tabular}{|c|c|c|c|c|c|c|c|}
\hline \multirow{2}{*}{$\begin{array}{l}\text { Character } \\
\text { (Table 2) }\end{array}$} & \multicolumn{2}{|c|}{ Sebastes marinus ${ }^{a}$} & \multicolumn{2}{|c|}{ Beaked redfishes $^{a}$} & \multirow{2}{*}{$\begin{array}{c}\text { Levene's } \\
\text { test }\end{array}$} & \multicolumn{2}{|c|}{ t-test } \\
\hline & Mean & $\mathrm{SE}$ & Mean & SE & & Before & After \\
\hline BODEPANA & 1.9649 & 0.0070 & 1.8801 & 0.0052 & $N S^{b}$ & ** & $\star \star$ \\
\hline BODEPPEC & 2.0781 & 0.0074 & 2.0042 & 0.0055 & $N S^{b}$ & $\star \star$ & $\star \star \star$ \\
\hline BODYWEIG & 2.9688 & 0.0205 & 2.7468 & 0.0147 & $N S^{b}$ & ** & NS \\
\hline BODYWIDT & 1.6952 & 0.0073 & 1.6278 & 0.0055 & $N S^{b}$ & ** & $\star \star$ \\
\hline CAUDPEDS & 1.5505 & 0.0066 & 1.4018 & 0.0052 & $N S^{b}$ & ** & $\star \star \star$ \\
\hline CRANRIDG & 1.1944 & 0.0068 & 1.1590 & 0.0054 & NS & $\star \star \star$ & $\star \star$ \\
\hline HEADLENG & 2.0671 & 0.0065 & 2.0101 & 0.0049 & NS & ** & $\star \star *$ \\
\hline INSIBEAK & 1.0438 & 0.0083 & 1.0229 & 0.0066 & NS & * & $\star \star \star$ \\
\hline INTEREYE & 1.4219 & 0.0069 & 1.3207 & 0.0047 & $\mathrm{NS}^{\mathrm{b}}$ & $\star \star$ & $\star *$ \\
\hline ORBIT & 1.5243 & 0.0056 & 1.5229 & 0.0044 & NS & NS & $\star \star \star$ \\
\hline OUTSBEAK & 0.5930 & 0.0075 & 0.6977 & 0.0074 & $* \mathrm{~b}$ & $\star \star$ & ** \\
\hline PECTBASE & 1.5042 & 0.0067 & 1.4145 & 0.0049 & $N S^{b}$ & ** & $\star *$ \\
\hline PECTLENG & 1.9402 & 0.0063 & 1.8912 & 0.0043 & $N S^{b}$ & ** & $\star \star$ \\
\hline POSTPECT & 2.2973 & 0.0061 & 2.2442 & 0.0045 & NS & ** & $\star \star *$ \\
\hline SNOTANAL & 2.3732 & 0.0071 & 2.2936 & 0.0049 & $N S^{b}$ & ** & NS \\
\hline SNOTDORS & 2.0189 & 0.0065 & 1.9618 & 0.0049 & NS & ** & $\star *$ \\
\hline SNOTLENG & 1.4356 & 0.0069 & 1.3577 & 0.0054 & $N S^{b}$ & $\star \star$ & NS \\
\hline STANLENG & 2.5415 & 0.0068 & 2.4665 & 0.0047 & $N S^{b}$ & ** & - \\
\hline
\end{tabular}

a Sample contained $165 \mathrm{~S}$. marinus and 269 beaked redfishes with values for all characters.

${ }^{b}$ Significant difference $(P<0.05)$ between variances before log-transformation.

TABLE 4. Summary of discriminant analyses of log-transformed data with the variables of each set listed in the order by which they entered their discriminant function. (Wilk's $\lambda$, in parentheses, is the multivariate test of equality of group centroids at each step after a new variable was entered into the function.)

\begin{tabular}{|c|c|c|c|}
\hline Item & $\begin{array}{c}\text { All variables } \\
(\text { Set } A)\end{array}$ & $\begin{array}{c}\text { Two variables } \\
\text { (Set B) }\end{array}$ & $\begin{array}{c}\text { All variables } \\
\text { except Set B } \\
\text { (Set C) }\end{array}$ \\
\hline Number of specimens ${ }^{a}$ & 434 & 446 & 437 \\
\hline $\begin{array}{l}\text { Variable names } \\
\text { and Wilk's } \lambda\end{array}$ & $\begin{array}{ll}\text { OUTSBEAK } & (0.510) \\
\text { ORBIT } & (0.447) \\
\text { INTEREYE } & (0.405) \\
\text { PECTBASE } & (0.399) \\
\text { BODEPPEC } & (0.387) \\
\text { CAUDPEDS } & (0.373) \\
\text { SNOTLENG }(0.366) \\
\text { SNOTANAL }(0.361) \\
\text { PECTLENG }(0.356) \\
\text { INSIBEAK } & (0.352) \\
\text { CRANRIDG } & (0.349)\end{array}$ & $\begin{array}{lr}\text { OUTSBEAK } & (0.508) \\
\text { ORBIT } & (0.445)\end{array}$ & $\begin{array}{ll}\text { INSIBEAK } & (0.755) \\
\text { INTEREYE } & (0.627) \\
\text { CRANRIDG } & (0.531) \\
\text { PECTLENG } & (0.495) \\
\text { CAUDPEDS } & (0.463) \\
\text { BODEPPEC }(0.443) \\
\text { PECTBASE }(0.431) \\
\text { SNOTLENG }(0.422) \\
\text { HEADLENG }(0.418)\end{array}$ \\
\hline $\begin{array}{l}\text { Resubstitution } \\
\text { classification }\end{array}$ & $91.5 \%$ & $87.2 \%$ & $89.9 \%$ \\
\hline $\begin{array}{l}\text { Jackknife } \\
\text { classification }\end{array}$ & $90.3 \%$ & $87.2 \%$ & $89.2 \%$ \\
\hline $\begin{array}{l}\text { Canonical correlation } \\
\text { squared }(\times 100)\end{array}$ & $65.1 \%$ & $55.5 \%$ & $58.2 \%$ \\
\hline
\end{tabular}

a Analysis (BMDP7M) performed on specimens with values for all variables (complete cases).

Wilk's $\lambda$ after entry into the function of OUTSBEAK and were 0.508 and 0.445 respectively, indicating good discriminatory power of the two characters. The function explained $55.5 \%$ of total variability.

The discriminant analysis of Set $\mathrm{C}$ morphometric characters (after adjustment by the covariate STANLENG) also showed good discrimination of the two groups (Table 4). The jackknife method correctly clas- sified $89.2 \%$ of the specimens and the resubstitution method classified $90.0 \%$. Partial F-values at the final step resulted in the following decrease in importance of the variables: INTEREYE (40.9), CAUDPEDS (40.6), BODEPPEC (29.5), CRANRIDG (20.9), PECTLENG (15.4), PECTBASE (13.3), SNOTLENG (13.0) and HEADLENG (4.9). The function explained $58.2 \%$ of the total variability, a slight increase in variability from that explained by the Set B function. 

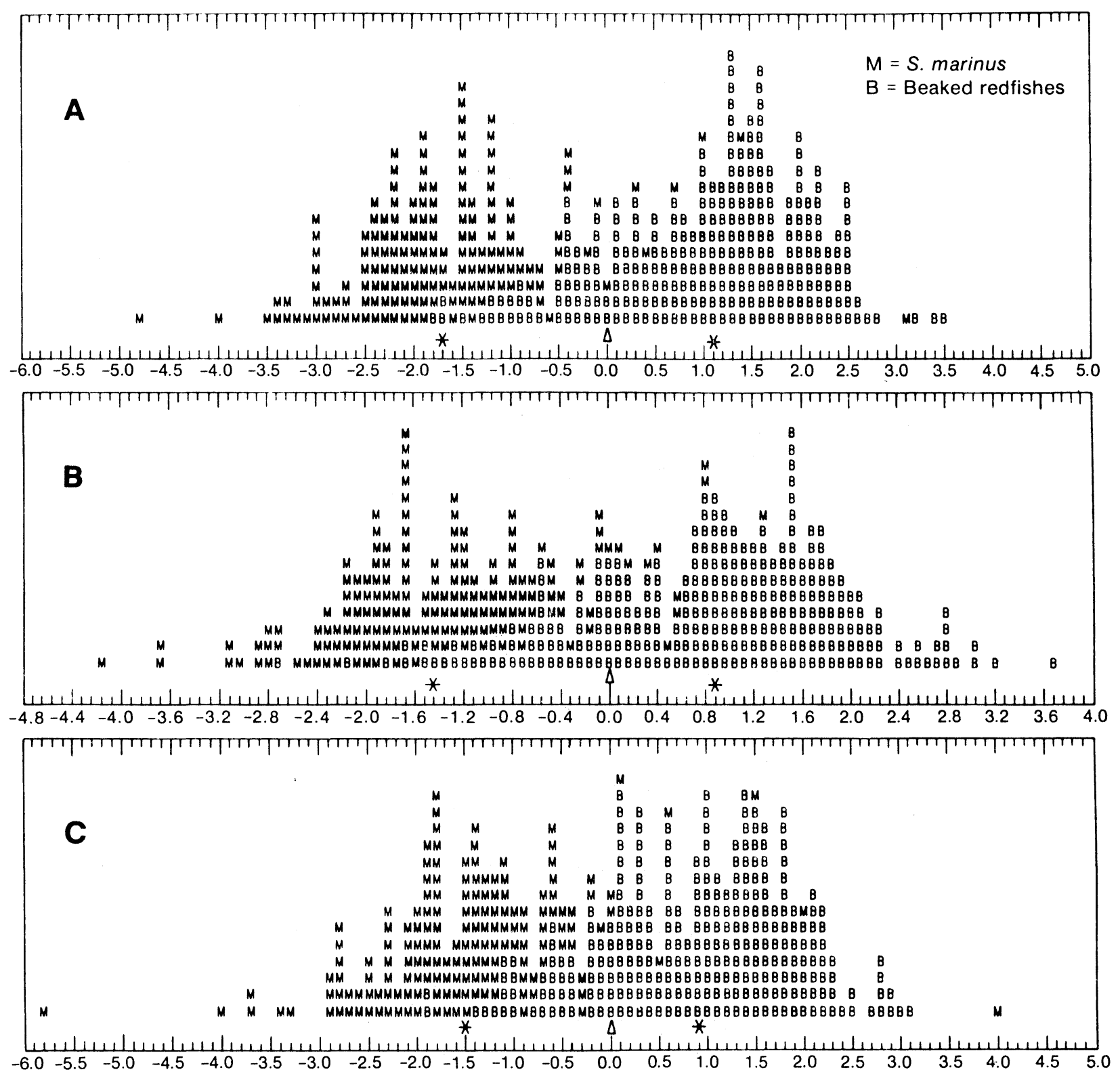

Fig. 2. Histograms of canonical function values from the discriminant analysis of $S$. marinus and beaked redfishes for data sets $A, B$ and $C$ (see Table 4). (On the axis, $\triangle$ indicates dividing point and $*$ the group means.)

Discriminant analyses of the three sets of variables performed well in separating S. marinus from beaked redfishes by the classification functions. The discriminant function with two variables (OUTSBEAK and ORBIT) did almost as well as the functions retaining 11 variables (Set $A$ ) and 9 variables (Set $C$ ). The histograms of the numbers of each species, evaluated by the canonical function in discriminant analyses of Sets A, $B$ and $C$ are shown in Fig. 2.

In conclusion, several morphometric characters can be considered of statistical value in discriminating between S. marinus and beaked redfishes (S. mentella and $S$. fasciatus). The traditional discriminators of Templeman and Sandeman (1957) ranked high among the characters retained by the discriminant function. Three other good characters (BODEPPEC, INTEREYE and CAUDPEDS) show species differences which can make separation of $S$. marinus and beaked redfishes more confident. Although several good discriminators were evident from the discriminant analyses, the following are suggested for use in field studies where quick and reliable methods are needed: OUTSBEAK (symphyseal tubercle generally long and sharp in beaked redfishes and blunt in S. marinus), ORBIT (eye smaller in S. marinus than in beaked redfishes of the 
same size), BODEPPEC (body depth at the pectorals larger in S. marinus), and CAUDPEDS (caudal peduncle wider in $S$. marinus than in beaked redfishes).

\section{Acknowledgements}

We thank E. J. Sandeman and W. Templeman for the privilege of using their data, E. M. LeGrow and personnel of the Redfish Section for collecting samples, J. M. Green and A. Singh of Memorial University of Newfoundland and D. B. Atkinson and J. C. Rice of the Fisheries Research Branch for their valuable comments during the preparation of this paper.

\section{References}

ANDERSON, T. W. 1958. An introduction to multivariate statistical analysis. John Wiley and Sons Inc., New York, NY, $374 \mathrm{p}$.

BARSUKOV, V. V. 1968. The systematic relationship of redfishes of the genus Sebastes of the Northwest Atlantic Ocean. Doklady Akad. Nauk SSSR, 183: 479-482. (Transl. from Russian in Doklady Biol. Sci., 183: 734-737.

BLISS, C. I. 1970. Statistics in biology, Vol. 2. McGraw-Hill Book Co., New York, NY, $639 \mathrm{p}$.

BROWN, M. B., and A. B. FORSYTHE. 1974. Robust tests for the equality of variances. J. Amer. Stat. Assoc., 69: 364-367.
COOLEY, W. W., and P. R. LOHNES. 1971. Multivariate data analysis. John Wiley and Sons Inc., New York, NY, 364 p.

DIXON, W. J., M. B. BROWN, L. ENGELMAN, J. W. FRANE, M. A. HILL, R. I. JENNRICH, and J. D. TOPOREK. 1981. BMDP statistical software. Univ. Calif. Press, Berkeley, CA.

KLECKA, W. P. 1975. Discriminant analysis. In Statistical package for the social sciences, N. H. Nie, C. H. Hull, J. G. Jenkins, K. Steinbrenner and D. H. Best (eds.), p. 434-467. McGraw-Hill, New York, NY, $675 \mathrm{p}$.

LACHENBRUCH, P. 1975. Discriminant analysis. MacMillan Publ. Co., New York, N.Y., $128 \mathrm{p}$.

LACHENBRUCH, P., and R. M. MICKEY. 1968. Estimation of error rates in discriminant analysis. Technometrics, 10: 1-11.

MISRA, R. K., and I-H Ni. 1983. Distinguishing beaked redfishes, Sebastes mentella and S. fasciatus, by discriminant analysis (with covariance) and multivariate analysis of covariance. Can. J. Fish. Aquat. Sci., 40: 1507-1511.

NEFF, N. A., and G. R. SMITH. 1978. Multivariate analysis of hybrid fishes. Syst. Zool., 28: 176-196.

NI, I-H. 1981. Separation of sharp-beaked redfishes, Sebastes fasciatus and $S$. mentella from northeastern Grand Bank by morphology of extrinsic gasbladder musculature. J. Northw. Atl. Fish. Sci., 2: 7-12.

MS 1981. Application of factor analysis in redfish morphological studies. ICES C.M. Doc., No. G:39, 14 p.

POWER, D. J., and I-H. NI. 1982. Morphology of the extrinsic gasbladder musculature in the golden redfish, Sebastes marinus. J. Northw. Atl. Fish. Sci., 3: 165-168.

TEMPLEMAN, W., and E. J. SANDEMAN. 1957. Two varieties of redfish in the Newfoundland area. Fish. Res. Board Can. Atlant. Prog. Rep., 66: 20-23. 
